\title{
Complexity in the high latitude HF radar spectral width boundary region
}

\author{
M. L. Parkinson, K. M. Hannah, and P. L. Dyson \\ Department of Physics, La Trobe University, Victoria 3086, Australia \\ Received: 31 August 2005 - Revised: 29 February 2008 - Accepted: 7 March 2008 - Published: 13 May 2008
}

\begin{abstract}
SuperDARN radars are sensitive to the collective Doppler characteristics of decametre-scale irregularities in the high latitude ionosphere. The radars routinely observe a distinct transition from large spectral width $\left(>100 \mathrm{~m} \mathrm{~s}^{-1}\right)$ located at higher latitudes to low spectral width $\left(<50 \mathrm{~m} \mathrm{~s}^{-1}\right)$ located at lower latitudes. Because of its equatorward location, the TIGER Tasmanian radar is very sensitive to the detection of the spectral width boundary (SWB) in the nightside auroral ionosphere. An analysis of the line-of-sight velocities and 2-D beam-swinging vectors suggests the meso-scale $(\sim 100 \mathrm{~km})$ convection is more erratic in the high spectral width region, but slower and more homogeneous in the low spectral width region. The radar autocorrelation functions are better modelled using Lorentzian Doppler spectra in the high spectral width region, and Gaussian Doppler spectra in the low spectral width region. However, paradoxically, Gaussian Doppler spectra are associated with the largest spectral widths. Application of the Burg maximum entropy method suggests the occurrence of double-peaked Doppler spectra is greater in the high spectral width region, implying the small-scale $(\sim 10 \mathrm{~km})$ velocity fluctuations are more intense above the SWB. These observations combined with collective wave scattering theory imply there is a transition from a fast flowing, turbulent plasma with a correlation length of velocity fluctuations less than the scattering wavelength, to a slower moving plasma with a correlation length greater than the scattering wavelength. Peak scaling and structure function analysis of fluctuations in the SWB itself reveals approximately scale-free behaviour across temporal scales of $\sim 10 \mathrm{~s}$ to $\sim 34 \mathrm{~min}$. Preliminary scaling exponents for these fluctuations, $\alpha_{\mathrm{GSF}}=0.18 \pm 0.02$ and $\alpha_{\mathrm{GSF}}=0.09 \pm 0.01$, are even smaller than that expected for MHD turbulence.
\end{abstract}

Correspondence to: M. L. Parkinson

(m.parkinson@latrobe.edu.au)
Keywords. Ionosphere (Auroral ionosphere; Ionospheremagnetosphere interactions) - Space plasma physics (Nonlinear phenomena)

\section{Introduction}

Super Dual Auroral Radar Network (SuperDARN) radars are over-the-horizon HF backscatter radars designed to map the large-scale high-latitude convection (Greenwald et al., 1985, 1995; Chisham et al., 2007). This is achieved by constraining a spherical harmonic model of electric potential to measurements of the line-of-sight Doppler velocity of 10-m scale Fregion ionospheric irregularities (Ruohoniemi et al., 1998). The latter are known to drift with the $\boldsymbol{E} \times \boldsymbol{B} / B^{2}$ velocity (Villain et al., 1985). The Doppler spectral widths are also measured, a parameter related to the lifetime of the irregularities and the spread of line-of-sight (LOS) velocity throughout the integration time and sampling volume.

SuperDARN radars routinely observe a distinct transition from large spectral widths $\left(>100 \mathrm{~m} \mathrm{~s}^{-1}\right)$ located at higher latitudes to low spectral widths $\left(<50 \mathrm{~m} \mathrm{~s}^{-1}\right)$ located at lower latitudes. The spectral width boundary (SWB) is sometimes a well defined feature and was shown to be a reasonable proxy for the open-closed magnetic field line boundary (i.e. the polar cap boundary) in the dayside ionosphere under $B_{z}$ southward conditions (Baker et al., 1995; Moen et al., 2001). It is also a reasonable proxy for the polar cap boundary in the pre-midnight sector of the nightside ionosphere (Lester et al., 2001; Parkinson et al., 2002; Chisham et al., 2004b), but not so in the post-midnight sector (Woodfield et al., 2002; Parkinson et al., 2004; Chisham et al., 2005).

The physical cause of the large spectral widths and the spectral width boundary observed by SuperDARN radars is

Published by Copernicus Publications on behalf of the European Geosciences Union. 
not very well understood. André et al. (2000) reviewed possible causes of large spectral widths including the effects of (1) the radar beams traversing shears in the large-scale convection, (2) small-scale $(\sim 10-\mathrm{km})$ convection vortices associated with filamentary field-aligned currents (Huber and Sofko, 2000), and (3) ULF waves in the Pc1-2 period range. The role of plasma diffusion and the lifetime of irregularities have been considered by Ponomarenko and Waters (2006, 2007).

Wright et al. (2004) showed a direct connection between the occurrence of artificial irregularities with moderate spectral widths and Pc1-2 wave activity, and Parkinson et al. (2003a) showed the occurrence of natural irregularities with large spectral widths coincident with intense, groundbased magnetic fluctuations. André et al. (2000) explained some of the large spectral widths by modelling the Doppler effects of ULF waves in the Pc 1-2 band. However, Ponomarenko and Waters (2003) reported an error in the calculus of the André et al. (2000) which over-estimated the effects of ULF waves by a factor of 2 .

Ponomarenko and Waters (2006) recommended modifications to the "FITACF" algorithm used to analyse the auto correlation functions (ACFs) recorded by SuperDARN radars. Their software modifications have been adopted by the wider SuperDARN community and reduce the magnitude of the spectral widths by $20-40 \%$. Ponomarenko and Waters (2007) subsequently analysed concurrent multifrequency observations of the spectral width and could not reconcile their results with Bohm diffusion which predicts an increase in spectral width with frequency. It is not known whether a similar SWB occurs when observing at MF and VHF frequencies.

Golovchanskaya et al. (2006) performed a statistical analysis of Dynamics Explorer 2 measurements of fluctuating electric and magnetic fields sorted according to the interplanetary magnetic field. Their clock dial plots reveal spatial variation in ionospheric turbulence reminiscent of the spatial variation of SuperDARN spectral widths (e.g. Villain et al., 2002, Fig. 5; Parkinson et al., 2003b, Fig. 8). Golovchanskaya (2007) postulated the source regions of turbulence are not necessarily magnetically conjugate in the magnetotail. Parkinson (2006a) and Able et al. (2006) performed generalised structure analysis (GSF) of HF radar velocity fluctuations and identified approximately scale-free regimes, often taken as evidence for a turbulent cascade.

Micro-scale turbulence $(\sim 100 \mathrm{~km})$ in the magnetospheric cusp has been directly observed using the CLUSTER spacecraft (Sundkvist et al., 2005). Indeed, polar orbiting satellites have observed intense electric field fluctuations close to the ionospheric cusp for several decades; these may be the signature of Alfvénic turbulence. Borovsky and Bonnel (2001) show how isolated circular vortices in the nightside plasma sheet map to east-west elongated vortices in the auroral ionosphere. Magnetospheric turbulence might map to small scales in the ionosphere and cause some very large radar spectral widths (cf. Fig. 1 of Parkinson et al., 1999b).

Spatial and temporal variations in the magnetospheric drivers causing large SuperDARN spectral widths will play an important role in forming the SWB. However, the SWB tends to form at the poleward edge of energetic electron precipitation $(\sim 1-10 \mathrm{keV})$ and thus a step-like increase in Pedersen conductance, $\Sigma_{p}$ (Parkinson et al., 2002, see their Fig. 6; Parkinson et al., 2004, 2005a). The increase in plasma density causing the increase in $\Sigma_{p}$ will tend to be concentrated in the E-region in the case of the discrete auroral oval. A SWB might form where $\Sigma_{p}$ becomes sufficiently large to short out the small-scale electric field fluctuations affecting the radar observations. More statistical and case studies using direct estimates of $\Sigma_{p}$ are needed to test this idea.

Ponomarenko and Waters (2007) related large F-region spectral widths to soft electron precipitation $(\sim 100 \mathrm{eV})$. They envisage the short lifetime $(10-20 \mathrm{~ms})$ of decametrescale ionospheric irregularities is directly driven by corresponding fluctuations in soft electron precipitation (and thus filamentary field-aligned currents). The roles of soft and energetic electron precipitation in regulating the spectral widths are not contradictory. Energetic electron precipitation is thought to increase the ionospheric conductance and thus suppress electric field and electric field fluctuation, whereas soft electron precipitation leads to the formation of smallscale irregularities with short lifetime and thus large spectral widths. These two effects will interact in complicated ways.

Achieving a comprehensive understanding the HF radar spectral widths is a difficult problem and so far no detailed, unifying theory is widely accepted. The combined effects of various phenomena will be important to a greater or lesser extent (ionospheric conductance, diffusion, energetic and soft particle precipitation, magnetospheric turbulence, ULF wave activity, etc.). The purpose of this paper is to report further complexity in the behaviour of the HF radar spectral width boundary and the convection of plasma flowing across it. Any satisfying theory of the SWB must account for the observed complexity.

\section{Experiment and analysis}

The Tasman International Geospace Environment Radar (TIGER) is a pair of SuperDARN radars located in Tasmania and New Zealand (Dyson and Devlin, 2000; Dyson et al., 2003, 2005). This study uses data recorded using the Tasmanian radar $\left(43.4^{\circ} \mathrm{S}, 147.2^{\circ} \mathrm{E} ; 55^{\circ} \Lambda\right)$ (hereafter “TIGER"). During common time operations (Greenwald et al., 1995; Chisham et al., 2007), SuperDARN radars scan $52^{\circ}$ of azimuth by electronically stepping the radar beam through 16 beam directions separated by $3.24^{\circ}$. The transmitter pulse width usually corresponds to $45 \mathrm{~km}$ of group range, and the first range gate is $180 \mathrm{~km}$, with 70 or more ranges separated 
by $45 \mathrm{~km}$. The integration time is usually 3 or $6 \mathrm{~s}$ per beam so that one full scan is completed every minute or two.

Parkinson et al. (2002) analysed observations of exceptional quality recorded using TIGER during 12:15 to 15:00 UT on 10 December 1999. Beam 4 was employed as a high time resolution "camping" beam interleaved between the 16-beams of routine scans. Beam 4 points down the magnetic meridian and is well suited to measuring the SWB when it is magnetically $L$-shell aligned. The chosen integration time was $3 \mathrm{~s}$; hence beam 4 was sampled once every $6 \mathrm{~s}$, and the total scan time was $16 \times 2 \times 3 \mathrm{~s}=96 \mathrm{~s}$. The observations revealed a distinct SWB which was a reasonable proxy for the nightside polar cap boundary throughout an interval of balanced dayside and nightside reconnection. The present study extends the analysis of these observations to reveal further complicated behaviour in the SWB.

TIGER was run in another special camping beam mode for approximately 32 days of discretionary time evenly spread throughout the $\sim 1$ year interval 4 December 2005 to 21 November 2006 (Parkinson, 2008 ${ }^{1}$ ). This mode consisted of repeatedly integrating for $1 \mathrm{~s}$ on beam 4 only. The idea was to establish a data base of relatively continuous 1-s resolution data to help define the fractal qualities of the velocity fluctuations observed above and below the SWB. Here fluctuation in the location of the SWB itself are analysed using peak scaling and generalised structure function (GSF) analysis, as described by Hnat et al. (2002a, b, 2003, 2005), Chapman et al. (2005), and Parkinson (2006a). These analyses provide a comprehensive decomposition of the statistical characteristics of fluctuating data.

The quality of the 1-s radar observations was tested by recording a set of beam 4 camping beam observations which interleaved 1-s and 6-s integration times. The concurrent data were recorded with all other conditions remaining the same (e.g. transmitter frequency, propagation conditions, irregularity growth and decay, etc.). Statistically, the error bars were larger for the 1-s radar observations. However, the range-time plots of backscatter parameters were essentially the same and the 60-fold increase in the number of samples compared to the 1-min common mode more than compensates for any loss of accuracy in the individual samples.

The sampling volume of SuperDARN beam-range pixels is defined as follows. Their size in group range is fixed by the equivalent $45 \mathrm{~km}$ pulse width. Their size in the cross beam direction increases with range because of the angular beam width, but it is $\sim 100 \mathrm{~km}$ at typical working ranges. The sampling volume in altitude is limited by the beam width in elevation, but in practice by where the radio waves become orthogonal to the magnetic field lines, a requirement for coherent backscatter from ionospheric irregularities. In this study,

\footnotetext{
${ }^{1}$ Parkinson, M. L.: Complexity in the scaling of electric field fluctuations in the high latitude F-region ionosphere, Ann. Geophys., submitted, 2008.
}

by "small-scales" we mean scales less than the $\sim 45 \times 100 \mathrm{~km}$ size of individual pixels in the radar maps.

The backscatter power (SNR in $\mathrm{dB}$ ), LOS Doppler velocity $\left(\mathrm{m} \mathrm{s}^{-1}\right)$, and the spectral width $\left(\mathrm{m} \mathrm{s}^{-1}\right)$ of echoes are estimated in real time using a standard pulse set scheme and analysis algorithm known as "FITACF" (Villain et al., 1987; Baker et al., 1995; Ponomarenko and Waters, 2006). The data used in this paper was reprocessed using the latest version of FITACF which reduces the magnitude of the spectral widths by $20-40 \%$, but the main qualitative results were obtained using the old version of FITACF.

The pulse set consists of 7 pulses each $\sim 300 \mu$ s wide and separated by a variable amount, but always an integer multiple of the fundamental lag length, $\tau=2400 \mu \mathrm{s}$. The pulse set was designed to measure large Doppler shifts at most ranges out to great ranges $(\sim 3330 \mathrm{~km})$, whilst minimising the detrimental effects of range aliasing. The pulse set permits the calculation of autocorrelation functions (ACFs) of the echoes out to lags of $18 \tau$ at all sampled ranges. Each pulse set lasts $\sim 88 \mathrm{~ms}$ and many individual ACFs are summed throughout a 3 or $6 \mathrm{~s}$ integration time.

The SuperDARN Doppler spectral widths are related to the lifetime of irregularities and the spread of LOS Doppler velocity, $v_{\text {LOS }}$, throughout the integration time and the sampling volume. FITACF calculates spectral widths by estimating how rapidly the ACFs de-correlate. A slow de-correlation implies a low spectral width, as might be obtained from relatively coherent targets such as land and sea, whereas a fast de-correlation implies a large spectral width in the corresponding Doppler spectrum. Results recorded using different integration times might differ because the de-correlation of the irregularities and ACFs is non-stationary.

When estimating the de-correlation of the ACFs, two models of a single peak in the corresponding Doppler spectra are used, namely Gaussian and Lorentzian spectral shapes (Hanuise et al., 1993). According to collective wave scattering theory, a Gaussian fit implies the correlation length of the velocity fluctuations is greater than the radar scattering wavelength, and the estimated spectral widths are a direct indication of the spread of $v_{\text {LOS }}$ in the sampling volume, whereas a Lorentzian fit implies the correlation length of the velocity fluctuations is smaller than the scattering wavelength, and the estimated spectral widths under-estimate the true spread of $v_{\text {LOS }}$ throughout the sampling volume (Hanuise et al., 1993).

Previous SuperDARN observations have shown the Lorentzian model provides a better fit to most polar cap data. However, the Gaussian model and another model which is Gaussian for small lags, but Lorentzian for long lags (Villain et al., 1996) provides a better fit to other echoes. Freeman (2003) argued that the underlying functional form of these different models is actually the same, with the moments of the distribution changing. The choice of the correct spectral width value is vexed: one strategy is to select spectral width values on an individual basis from the minimum of the fit errors, but this approach is not necessarily valid because 
an incorrect model may provide the best fit to some of the observations.

The FITACF approach provides reliable estimates of $v_{\text {LOS }}$ and spectral width when the corresponding Doppler spectrum is dominated by a single peak with good SNR. However, a Burg spectrum method has been used to show numerous ACFs correspond to multi-peak Doppler spectra (Schiffler et al., 1997; Huber and Sofko, 2000). Danskin et al. (2004) employed an 8th order Burg analysis to infer the presence of multiple peaks in E-region Doppler spectra. The same analysis of Danskin et al. (2004) was employed here to infer the presence of multi-peaked Doppler spectra. The Burg method is an autoregressive method which fits statistical models to the ACFs to generate information at a spectral resolution exceeding that obtained by using the discrete Fourier transform (DFT). However, artefacts are generated when the order of the fit is too large. Here we selected the most significant features by only considering the two dominate peaks when they had a SNR $>12 \mathrm{~dB}$, and their difference in SNR was $<6 \mathrm{~dB}$.

\section{Observations and results: a case study}

Figure 1 shows the analysis of observations made on TIGER beam 4 during 12:15 to 15:00 UT on 10 December 1999. Figure 1, parts (a), (b), and (d) are a reproduction of Fig. 3 in Parkinson et al. (2002). However, the spectral widths are smaller in magnitude because the data was reprocessed with the latest version of FITACF. The SWB has been superimposed in each panel (the bold, fluctuating curve near magnetic latitude $-69^{\circ}$ ). It was identified using the C-F algorithm (Chisham et al., 2003, 2004a), slightly modified to suit this 6-s resolution camping beam data (Parkinson et al., 2004). The SWB during this event was a reasonable proxy for the polar cap boundary (Parkinson et al., 2002). Here we concentrate on complicated behaviour in the data not previously discussed.

Figure 1a shows the backscatter power estimated using FITACF. For volume scatter off targets of equal radar cross section, the backscatter power should decrease as $R^{-1}$ where $R$ is the group range. However, at HF, the backscatter power can decrease as $\sim R^{-a}$ where $a$ can be $\sim 4$ due to refractive defocusing (Walker et al., 1987). There was no sharp decrease in the backscatter power aligned with the SWB; there were even patches of backscatter power $>36 \mathrm{~dB}$ above the SWB. For this event, the weak decline in backscatter power with range implies the existence of intense decametre-scale irregularities (i.e. large $\delta n / n$ ) in the polar cap ionosphere. Nevertheless, the panel provides no clear evidence for a well defined transition in the irregularities.

Figure $1 \mathrm{~b}$ shows that $v_{\text {LOS }}$ was generally more bursty in the polar cap, and rapidly decayed in amplitude, and became more homogeneous equatorward of the SWB. This effect was not confined to a single beam direction. Figure 1c shows the 2-D flow vectors estimated along beam 4 using the beam- swinging algorithm of Ruohoniemi et al. (1998). The flow speeds are indicated by both the length of the vectors and the colour scale. There was a succession of flow bursts to $>1 \mathrm{~km} \mathrm{~s}^{-1}$ across the SWB, penetrating to the closed field line region of the auroral oval. The results suggest the mesoscale convection $(>100 \mathrm{~km})$ became more homogeneous as the F-region plasma drifted across the SWB. However, the decay of the 2-D flow vectors across the SWB was not as closely aligned with the SWB as the decay of $v_{\text {LOS. This was }}$ partly due to the estimation of 2-D flow using beam swinging which assumes the velocity was constant with L-shell across all 16 radar beams, whereas there is azimuthal structure in both the 2-D flow and the SWB. Errors associated with this problem were modelled by Freeman et al. (1991).

Figure 2 examines the change in the statistical properties of the 2-D flow speeds (left column) and directions (right column) across the SWB. The probability distributions were calculated using all the vectors found (a), (b) poleward of $3^{\circ}$ poleward of the SWB (i.e. poleward of the SWB- $3^{\circ}$ ), (c) (d) in the poleward window SWB- $3^{\circ}$ to SWB- $1^{\circ}$, (e), (f) in the equatorward window $\mathrm{SWB}+2^{\circ}$ to $\mathrm{SWB}+3^{\circ}$, and (g), (h) equatorward of the $\mathrm{SWB}+3^{\circ}$. These window locations were chosen to emphasise the effect of the SWB, but the same qualitative result was obtained when using windows symmetric about the SWB.

Figure 2a shows that the mode value of the flow speed deep in the polar cap was only $\sim 30 \mathrm{~m} \mathrm{~s}^{-1}$, but the flow was often punctuated by flow bursts $>260 \mathrm{~m} \mathrm{~s}^{-1}$. These flow bursts pulled the average up to $165 \mathrm{~m} \mathrm{~s}^{-1}$. Figure $2 \mathrm{~b}$ shows the flow directions were spread, though predominantly towards the east and equatorward, as occurs at the start of the morning convection cell. Figure 2c, d shows that just poleward of the SWB, the flows were highly erratic, with numerous flow bursts pulling the average up to $498 \mathrm{~m} \mathrm{~s}^{-1}$ (off scale). The flow directions were beginning to concentrate in a single direction.

Figure $2 \mathrm{e}, \mathrm{f}$ shows the probability distributions of the flow just equatorward of the SWB underwent a transition to homogeneous flow. The mode value of the flow speeds was shifted upward to $290 \mathrm{~m} \mathrm{~s}^{-1}$, but there were proportionally fewer strong flow bursts, so the average flow speed, $331 \mathrm{~m} \mathrm{~s}^{-1}$, was smaller than that found immediately above the SWB. The flow directions were now clearly focussed into a narrow range, with $67 \%$ of the flow directions in the $100^{\circ}$ $120^{\circ}$ bin. Figure $2 \mathrm{~g}$, h shows that the flows remained homogeneous further equatorward, and the average flow speed decreased to $206 \mathrm{~m} \mathrm{~s}^{-1}$. In summary, the intermittency of the flows increased leading up to the SWB, and then became more homogeneous equatorward of the SWB.

Flow bursts across the nightside OCB are thought to be the signatures of bursty bulk flows (De la Beaujardière et al., 1994), widely interpreted as the signatures of magnetic reconnection in the magnetotail.

Figure 1d shows the spectral widths determined by FITACF (Ponomarenko and Waters, 2006). Lorentzian or 


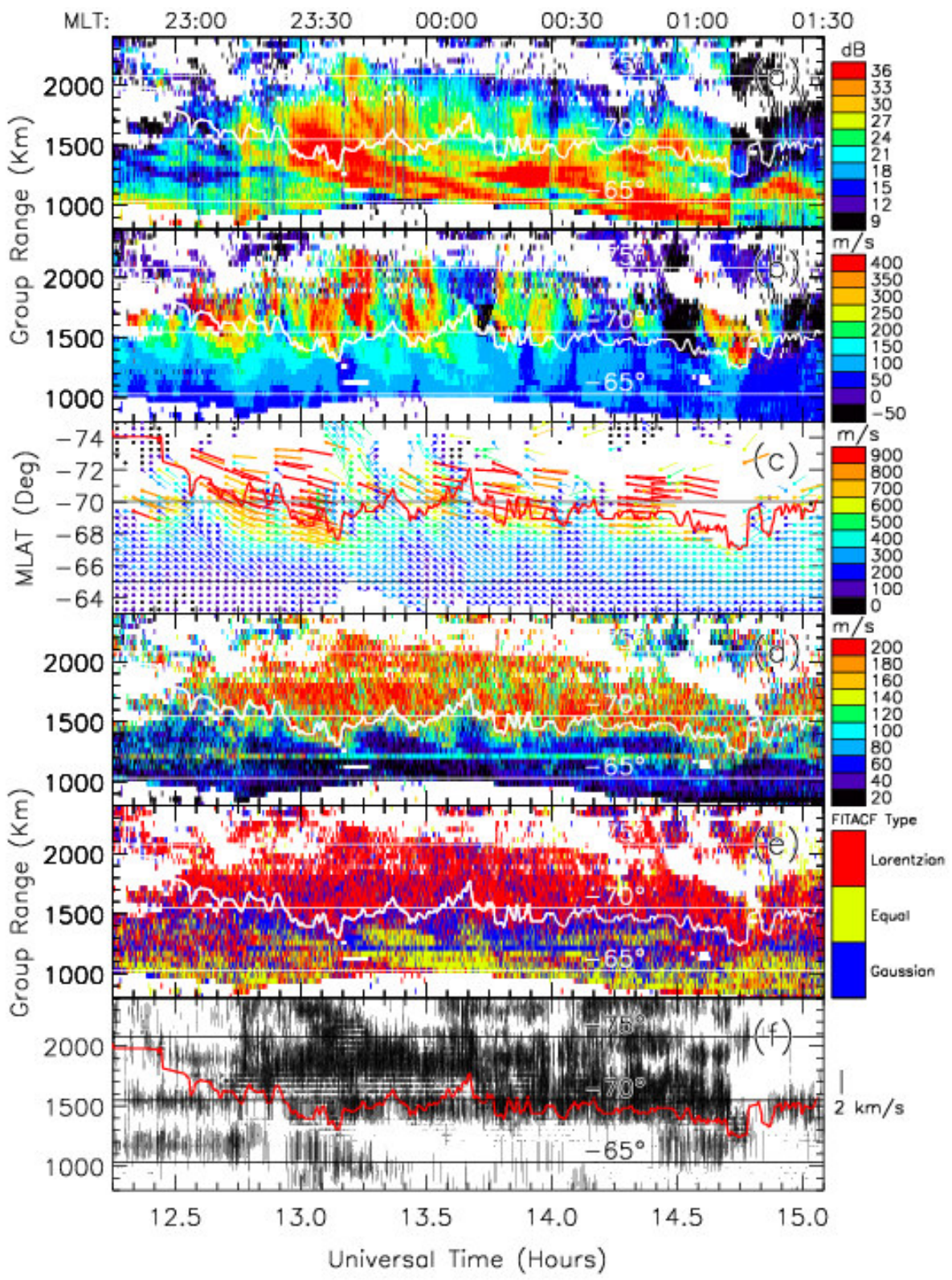

Fig. 1. All six panels show range-time plots of results calculated using TIGER Tasmania observations recorded at frequency $11.9 \mathrm{MHz}$ on beam 4 during 12:15 to 15:00 UT on 10 December 1999. The three thin, horizontal lines in all panels represent corrected geomagnetic latitudes of $-65^{\circ},-70^{\circ}$, and $-75^{\circ}$. The SWB has been superimposed in all panels (the bold, fluctuating curve near magnetic latitude $-69^{\circ}$ ). (a) FITACF backscatter power (SNR, dB). (b) FITACF line-of-sight Doppler velocity, $v_{\text {LOS }}\left(\mathrm{m} \mathrm{s}^{-1}\right)$. (c) 2-D beam-swinging vectors estimated using $v_{\text {LOS }}$ recorded on all 16 beams. The solid dots correspond to the time and latitude of the velocity estimate, and the flows are in the direction of the lines leaving the dots. The magnitude of the flows are indicated by the colour bar. (d) FITACF spectral width assuming a single peak $\left(\mathrm{m} \mathrm{s}^{-1}\right)$. (e) The FITACF spectral shape, Gaussian or Lorentzian, which gave the smallest fit error (see the text for an explanation). (f) The occurrence of doubled-peaked spectra identified using the Burg analysis. The length of the vertical lines indicate the separation between the two main peaks using a scale of $10 \mathrm{~m} \mathrm{~s}^{-1} \mathrm{~km}^{-1}$.

Gaussian spectral widths were plotted depending on which model produced the minimum fit error on an individual basis. Depending on the cause of the large spectral widths, the SWB implies the lifetime of the irregularities were shorter $(\sim 10-20 \mathrm{~ms})$ or small-scale electric field fluctua- tions $(\sim 10 \mathrm{~km}$ in space and $\sim 1 \mathrm{~s}$ in time) were more intense above the SWB. The meso-scale flow speeds (Fig. 1b) did not decrease as rapidly as the spectral widths across the SWB. Because the boundary is more clearly defined in the realm of small-scale fluctuations (i.e. the spectral widths), 


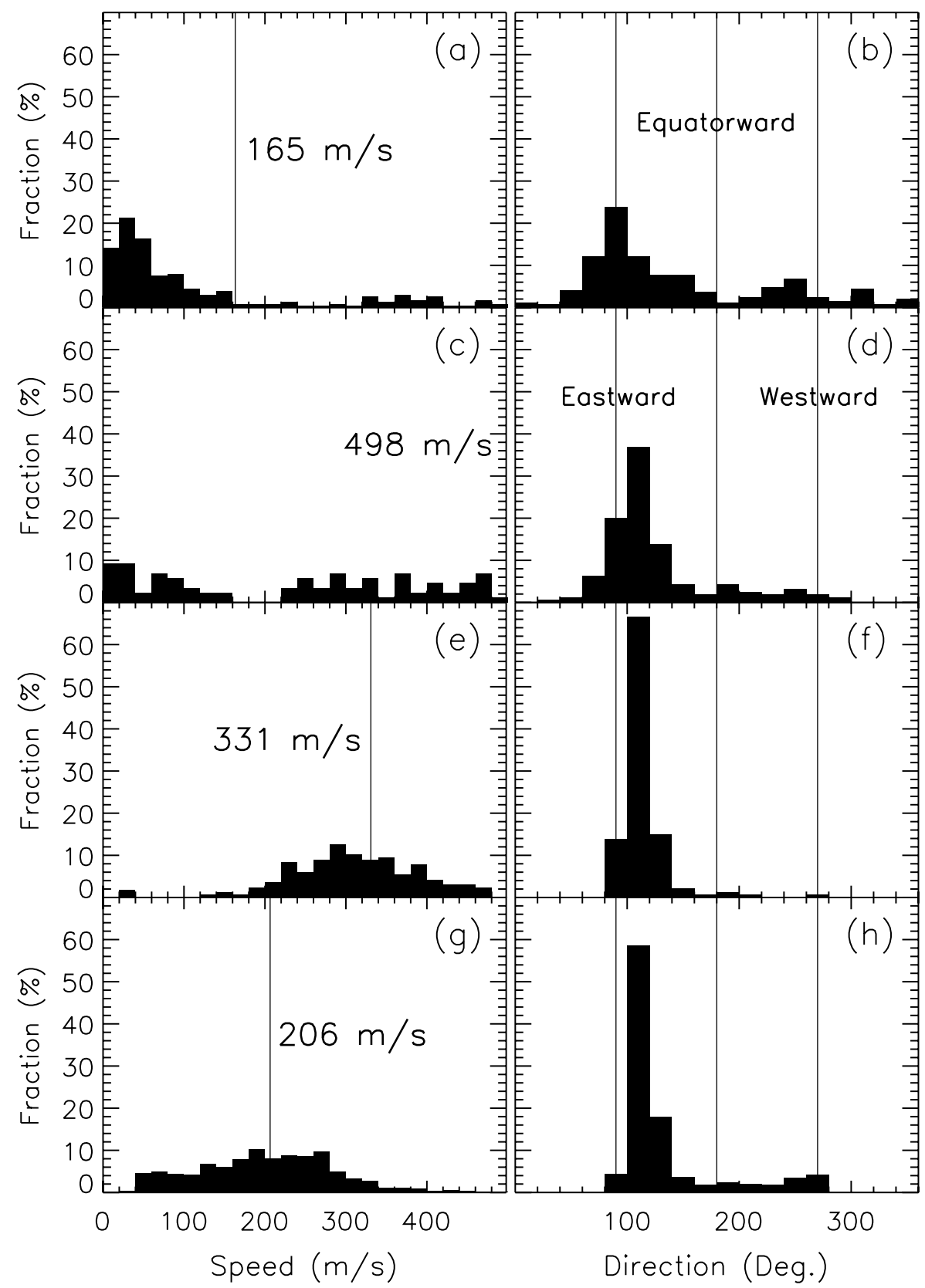

Fig. 2. (a) The change in the probability distributions of 2-D flow speeds (left column) and directions (right column) across the SWB during 12:15 to 15:00 UT on 10 December 1999. The "fractions (\%)" represent the fraction of the total number of samples for all vectors found (a), (b) poleward of the SWB- $3^{\circ},(\mathbf{c}),(\mathbf{d})$ in the poleward window SWB- $3^{\circ}$ to SWB- $1^{\circ},(\mathbf{e}),(\mathbf{f})$ in the equatorward window $\mathrm{SWB}+2^{\circ}$ to $\mathrm{SWB}+3^{\circ}$, and $(\mathbf{g}),(\mathbf{h})$ equatorward of the $\mathrm{SWB}+3^{\circ}$ (latitudes and SWBs are negative in the Southern Hemisphere). Average flow speeds are superimposed in the left column. Bin sizes of $20 \mathrm{~m} \mathrm{~s}^{-1}$ in flow speed and $20^{\circ}$ in flow direction were used. A flow direction of $0^{\circ}$ is poleward, $90^{\circ}$ eastward, and $180^{\circ}$ equatorward in magnetic coordinates.

the physical process controlling the formation of the SWB must exert a greater influence at smaller scales.

There was more structure in the distribution of spectral width than a single step-like decrease across the SWB. Above the SWB, "patches" of large spectral width $\left(>250 \mathrm{~m} \mathrm{~s}^{-1}\right)$ expanded equatorward through a general back- ground of moderate spectral width $\left(\sim 100 \mathrm{~m} \mathrm{~s}^{-1}\right)$. Below the SWB, patches of low spectral width $\left(\sim 75 \mathrm{~m} \mathrm{~s}^{-1}\right)$ expanded equatorward through a general background of very low spectral width $\left(<30 \mathrm{~m} \mathrm{~s}^{-1}\right)$. Although not clear, there is a rough relationship between the occurrence of patches of equatorward expanding flow burst and spectral width (Fig. 1b, d). In 


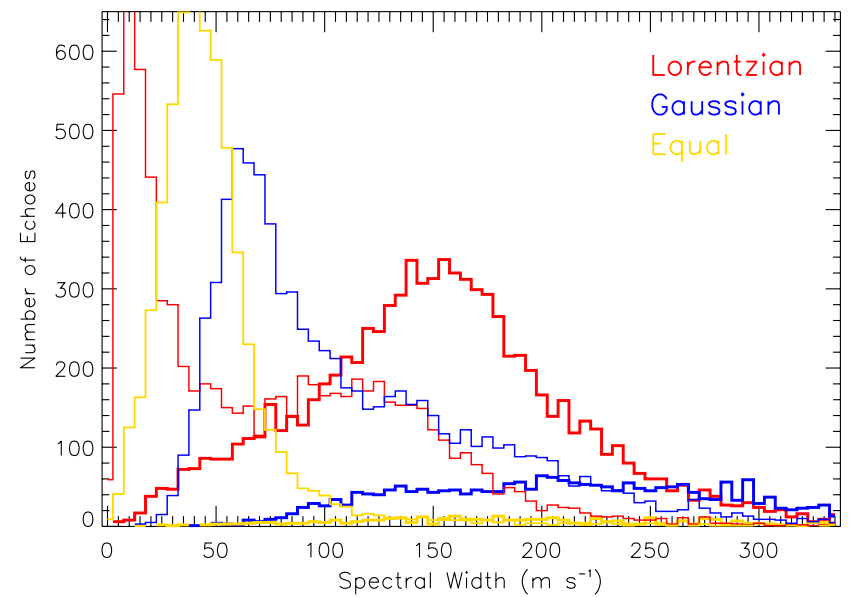

Fig. 3. A set of histograms showing the number of echoes found within $5 \mathrm{~m} \mathrm{~s}^{-1}$ bins of spectral width on beam 4 during the interval, 12:15 to 15:00 UT on 10 December 1999. The results have been sorted according to spectral fit type: Lorentzian fit (red), indeterminate fit (yellow), and Gaussian fit (blue); and into categories above (bold) and below (thin) the SWB.

general, the spectral widths increase with velocity, but so far no significant correlation between structure in the meso- and small-scale velocity has been identified.

Figure 1e is a map showing whether the Lorentzian fit (red) or the Gaussian fit (blue) had the smallest fit error. If the two spectral fit errors were equal to within the precision of the errors returned by FITACF, the spectral shape was designated "equal" (yellow), or indeterminate. It can be seen that Lorentzian spectral shape was prevalent above the SWB, whereas the Gaussian shape was prevalent below the SWB. A Lorentzian shape implies the correlation length of the velocity fluctuations was smaller than the scattering wavelength, whereas a Gaussian shape implies the correlation length of the velocity fluctuations was greater than the radar scattering wavelength. Hence we can infer the velocity fluctuations at "kinetic" scales $(\sim 10 \mathrm{~m})$ decreased when the plasma drifted across the SWB.

Again, there was more structure in the distribution of spectral shape than a single step-like decrease across the SWB. Above the SWB, there were small isolated patches of Gaussian spectral shape scattered amongst the predominantly Lorentzian shapes. Below the SWB, patches of Gaussian shape expanded equatorward through a general background of indeterminate shape. Although there was a tendency for patches of higher $v_{\mathrm{LOS}}$, spectral width, and spectral shape (Fig. 1b, d, e) to coincide, the relationship was not one-to-one, as might be the case if there were a simple linear relationship between the different parameters.

The complicated relationship between spectral width and spectral shape is examined further in Fig. 3. The SWB was identified at every instant throughout the study interval (Fig. 1 white curves). This enabled us to sort the ionospheric

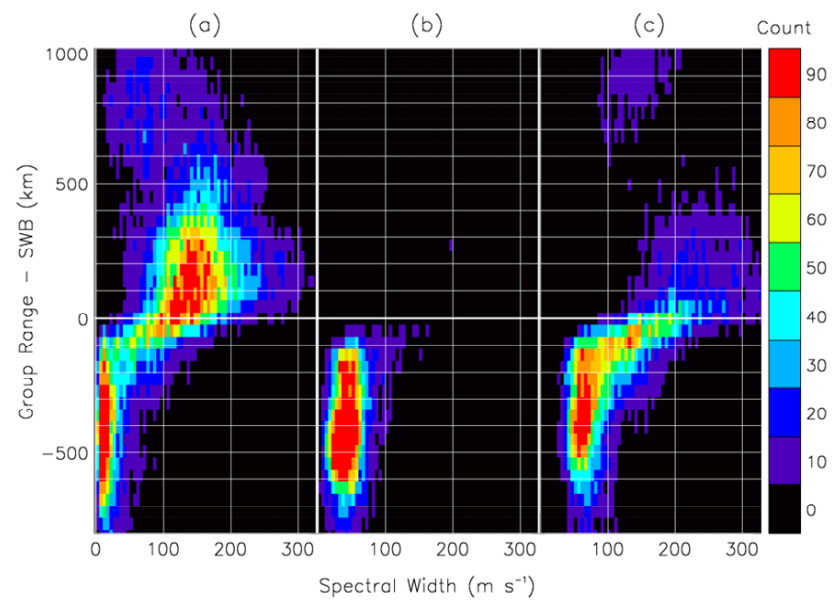

Fig. 4. Colour pixel maps showing the number of echoes versus $5-\mathrm{m} \mathrm{s}^{-1}$ bins of spectral width and for $45-\mathrm{km}$ steps of group range relative to the location of the SWB during the interval, 12:15 to 15:00 UT on 10 December 1999. The results have been sorted according to spectral fit type, (a) Lorentzian best fits, (b) indeterminate best fits, and (c) Gaussian best fits. The colour scale is proportional to the number of counts: black $(\leq 5)$, purple $(>5$ to $\leq 15), \ldots$, red $(>85)$.

echoes into two categories, namely those found above and below the SWB. Figure 3 shows histograms of the number of echoes with better Lorentzian fit (red), Gaussian fit (blue), and indeterminate fit (yellow), sorted into categories above (bold) and below (thin) the SWB.

Figure 1d shows a horizontal bar at range $1215 \mathrm{~km}$. Data recorded at this range are often erroneous due to bad lags in the ACFs and have been rejected in the following analyses.

Above the SWB there were more Lorentzian fits than Gaussian fits, but the Gaussian fits were biased toward larger spectral width. The mode value for the Lorentzian fits was $\sim 155 \mathrm{~m} \mathrm{~s}^{-1}$ compared with $\sim 200 \mathrm{~m} \mathrm{~s}^{-1}$ for the Gaussian fits $\left(5 \mathrm{~m} \mathrm{~s}^{-1}\right.$ bin sizes). There was a small, residual population of indeterminate spectral fits, and the majority of ACFs were resolved into one of the two main spectral types above the SWB.

Below the SWB there were more Gaussian fits than Lorentzian fits, and the bias of Gaussian fits toward larger spectral width was more pronounced. The mode value for the Lorentzian fits was $\sim 10 \mathrm{~m} \mathrm{~s}^{-1}$, contrasting with $\sim 60 \mathrm{~m} \mathrm{~s}^{-1}$ for the Gaussian fits. Below the SWB, the population of indeterminate spectral fits was large and had a mode value of $\sim 40 \mathrm{~m} \mathrm{~s}^{-1}$. The indeterminate spectral fits bridged the gap between the Gaussian and Lorentzian spectral fits, consistent with the notion that the two spectral models are a manifestation of a single, underlying model (Freeman, 2003).

Figure 1b, d, e shows that larger velocities and spectral widths, and more Lorentzian spectral fits, were found poleward of the SWB. Thus it seems reasonable to associate Lorentzian spectral fits with larger velocities and spectral 
widths. It is true that there are more Lorentzian fits with large spectral width when the distributions of spectral width are not sorted into categories above and below the SWB. However, Fig. 3 demonstrates that, paradoxically, Gaussian spectral fits were associated with larger spectral widths, both above and below the SWB. When a similar set of histograms of $v_{\text {LOS }}$ were generated, there was only a weak bias of Lorentzian fit toward higher velocity. Many of the Lorentzian fits were actually associated with small velocities found above the SWB.

The variation of spectral width and spectral shape across the SWB is examined in greater detail in Fig. 4. A moving window of 3 group ranges was stepped through each range separated by $45 \mathrm{~km}$, and the number of echoes within 5 $\mathrm{m} \mathrm{s}^{-1}$ bins of spectral width were counted. The group range of every ionospheric echo relative to the SWB was identified. Thus Fig. 4 is a pixel map of the number of echoes versus spectral width and meridional distance relative to the SWB for each of the three spectral fit types.

Consistent with the histograms shown in Fig. 3, the Lorentzian spectral widths in Fig. 4a had a very low mode value $\sim 10 \mathrm{~m} \mathrm{~s}^{-1}$ well below the SWB, but increased to a mode value $\sim 160 \mathrm{~m} \mathrm{~s}^{-1}$ above the SWB. The large spectral widths $>80 \mathrm{~m} \mathrm{~s}^{-1}$ below the SWB were associated with flow bursts originating above the SWB. Deep into the polar cap, $\sim 810 \mathrm{~km}$ poleward of the SWB, there was another population of modest spectral widths with mode $\sim 65 \mathrm{~m} \mathrm{~s}^{-1}$ associated with the regions of stagnant polar cap flow shown in Fig. 1b (purple).

The indeterminate spectral widths in Fig. $4 \mathrm{~b}$ had a strong peak below the SWB, located between the peaks in parts (a) and (c). Indeterminate spectral widths probably represent an intermediate spectral type.

The Gaussian spectral widths in Fig. 4c were generally larger than the other two types. There was weak evidence for the bifurcation of the distributions from $\sim 100 \mathrm{~km}$ to $300 \mathrm{~km}$ below the SWB. Deep into the polar cap, $\sim 810 \mathrm{~km}$ poleward of the SWB, there was a population of modest spectral widths with mode $\sim 140 \mathrm{~m} \mathrm{~s}^{-1}$ associated with the regions of stagnant polar cap flow shown in Fig. 1b (purple).

Figure 1f shows the occurrence of double-peaked Doppler spectra inferred from the Burg analysis of the ACFs (Danskin et al., 2004). The short vertical lines are centred on the time and range where the double-peaked spectra were identified, and the length of the vertical lines are proportional to the separation between the two peaks in Doppler velocity using a scale of $10 \mathrm{~m} \mathrm{~s}^{-1} \mathrm{~km}^{-1}$. Periodic horizontal bands separated by the range resolution of $\sim 45 \mathrm{~km}$ appear where the separation between many peaks was relatively small, in the order of $100 \mathrm{~m} \mathrm{~s}^{-1}$. Unlike the results of Huber and Sofko (2000), our calculations also revealed double peaks separated by more than $400 \mathrm{~m} \mathrm{~s}^{-1}$. The majority of the double-peaked spectra were concentrated above the SWB in regions several degrees wide in latitude, with their SNR tending to increase toward the SWB.
Figure 5 illustrates some individual results of the Burg analysis. This is an arbitrary selection of Burg spectra calculated using data at eight ranges between $1980 \mathrm{~km}$ and $2295 \mathrm{~km}$ and recorded at 13:15 UT. The low resolution Doppler spectra calculated using a DFT are drawn using light curves, whereas the corresponding Burg spectra have been superimposed in bold. Using our selection criteria, doublepeaked spectra in this set occurred at ranges 1980, 2160, 2205,2250 , and $2295 \mathrm{~km}$, and with a broad range of separations between the two main peaks. Overall, the Burg results also suggest a decrease in small-scale circulation as the plasma drifted across the SWB. Radar observations with improved Doppler resolution are required to help decide upon the reality of these features.

\section{Estimation of spectral width boundary (SWB) loca- tion}

As discussed in Sect. 2, a special 1-s time resolution mode was run on TIGER to support a comprehensive analysis of the statistical properties of fluctuations in SWB location (Parkinson, 2008 ${ }^{1}$ ). Approximately 2.8 million 1-s integrations were performed on beam 4 during 32 days evenly spread throughout 4 December 2005 to 21 November 2006. However, the availability of sufficient ionospheric scatter meant that only 113538 SWBs were identified. Here we discuss various techniques used to estimate the SWB location.

Chisham et al. (2003, 2004a) developed the "C-F" algorithm for estimating the SWB location. It consists of applying a median filter to the spectral width samples recorded on adjacent beams in azimuth and samples in time. The C-F algorithm was not suitable for analysing our 1-s resolution data measured using a single beam. A median filter might also reject some statistically significant events. Various methods can be used to estimate the SWB location including the requirement for "inertia" in the spectral width values found above and below some threshold chosen to separate the two populations of spectral widths.

Here we estimated the SWB location by identifying the group range at which the spectral width was less than a chosen threshold $\left(100 \mathrm{~m} \mathrm{~s}^{-1}\right)$ yet the spectral width at the next range was greater than the threshold. There also had to be a spectral width value less than threshold at the range immediately equatorward of the SWB location, and the median of the three spectral widths above the SWB location had to be greater than the threshold. This ensured the SWB was not identified by an isolated fluctuation. Various permutations of this algorithm and the chosen threshold can be used and they give similar results.

The behaviour and characteristics of the SWB can change with magnetic local time (Chisham, 2004a, 2005) and geomagnetic conditions (Parkinson et al., 2005a). The SWB is sometimes a distinct, sharp feature, especially when the spectral widths are median filtered. The SWB can also 

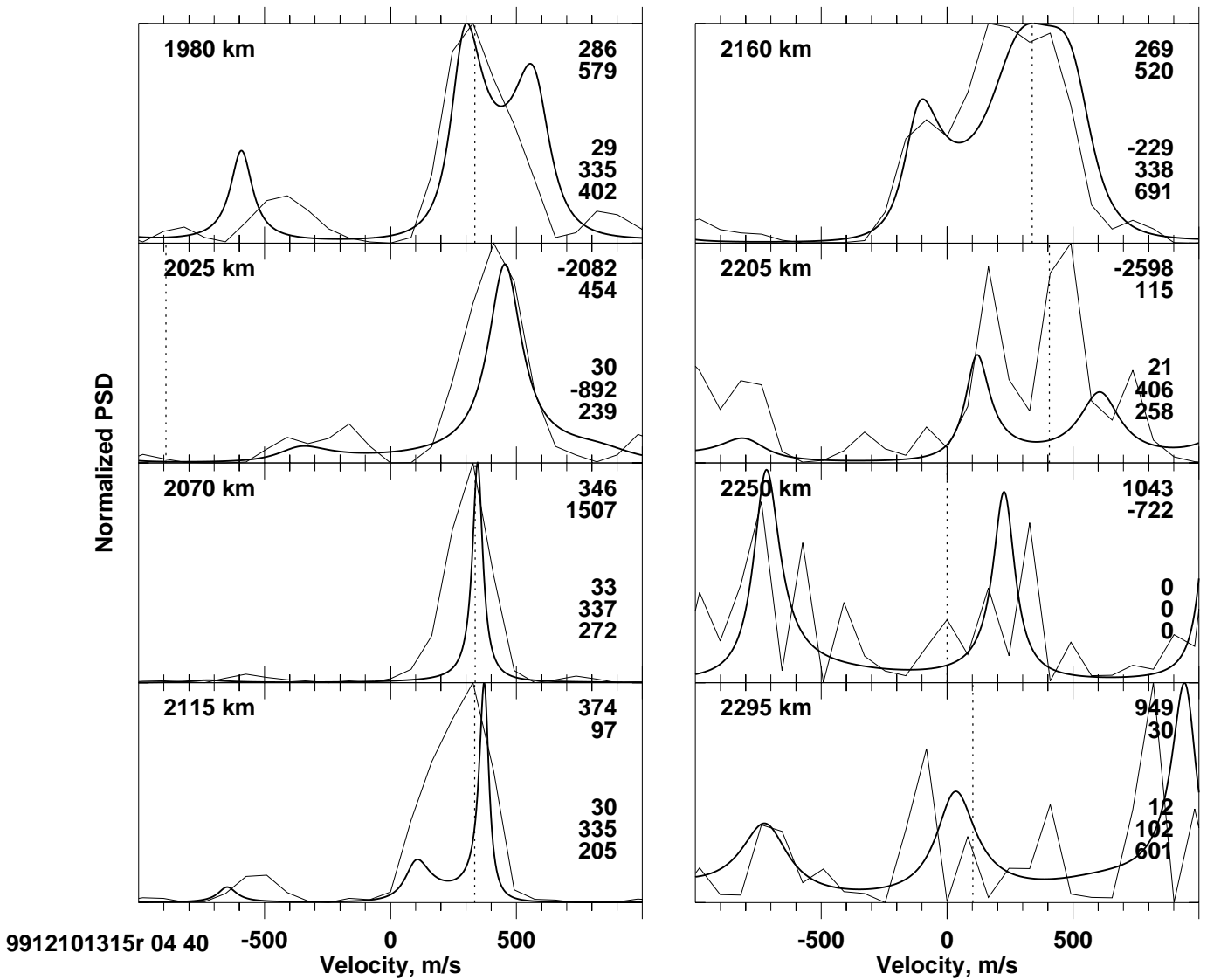

Fig. 5. Eight examples of DFT Doppler spectra (light curves) and Burg spectra (bold curves) calculated using ACFs recorded on beam 4 between ranges $1980 \mathrm{~km}$ and $2295 \mathrm{~km}$ at 13:15 UT on 10 December 1999. In each panel, the Doppler velocities of the two main peaks are given at top right, and the FITACF power, line-of-sight velocity, and spectral width are given at bottom right. The spectra at all ranges except 2025, 2070, and $2115 \mathrm{~km}$ are double-peaked spectra using our selection criteria.

correspond to a relatively gradual increase in spectral widths (Parkinson et al., 2004). However, in general, the SWB has a stochastic quality because of constant fluctuations in the spectral widths found both above and below the SWB.

Figure 6 shows one hour of 1-s spectral widths observed on beam 4 during 11:00 to 12:00 UT on 17 December 2005. The bold fluctuating line in panel (a) represents the equatorward locus of the first SWB identified per integration as described above, and is similar to the SWB which would be identified visually and using the C-F algorithm. However, spectral width values smaller and larger than the threshold are observed above and below the SWB. Thus it is possible to identify multiple, concurrent SWBs, as shown in panel (b), where up to 5 SWB were identified per integration.

The SWB has an ephemeral quality, but the first identified SWB is a clearly recognisable feature. This boundary has been used in the subsequent analyses.

\section{Peak scaling and GSF analyses}

Peak scaling and Generalised Structure Function (GSF) analyses have been applied to the solar wind (Hnat et al., 2002a, 2003; Parkinson et al., 2007), magnetosphere (Hnat et al., 2002b, 2005), and ionosphere (Able et al., 2006; Parkinson, 2006a, 2008 ${ }^{1}$ ). These techniques can be used to characterise the statistical properties of data across a broad range of spatial and temporal scales. Here we apply them to the unevenly spaced time series of SWB locations estimated using the 1-S data recorded at discrete group range intervals of $45 \mathrm{~km}$.

Peak scaling and GSF analyses and associated technical problems have been described in the afore-mentioned papers. Parkinson (2008) ${ }^{1}$ applied these techniques to the analysis of the Doppler velocities for the same 1-s data set, and the present data have been conditioned in the same way. It is important to adopt a consistent approach to permit intercomparison of the results for different data sets. The choices made here (e.g. scaling limits) are consistent with previous studies and the account given is brief for the benefit of the reader. The aim here is to present preliminary results for the SWB locations. 


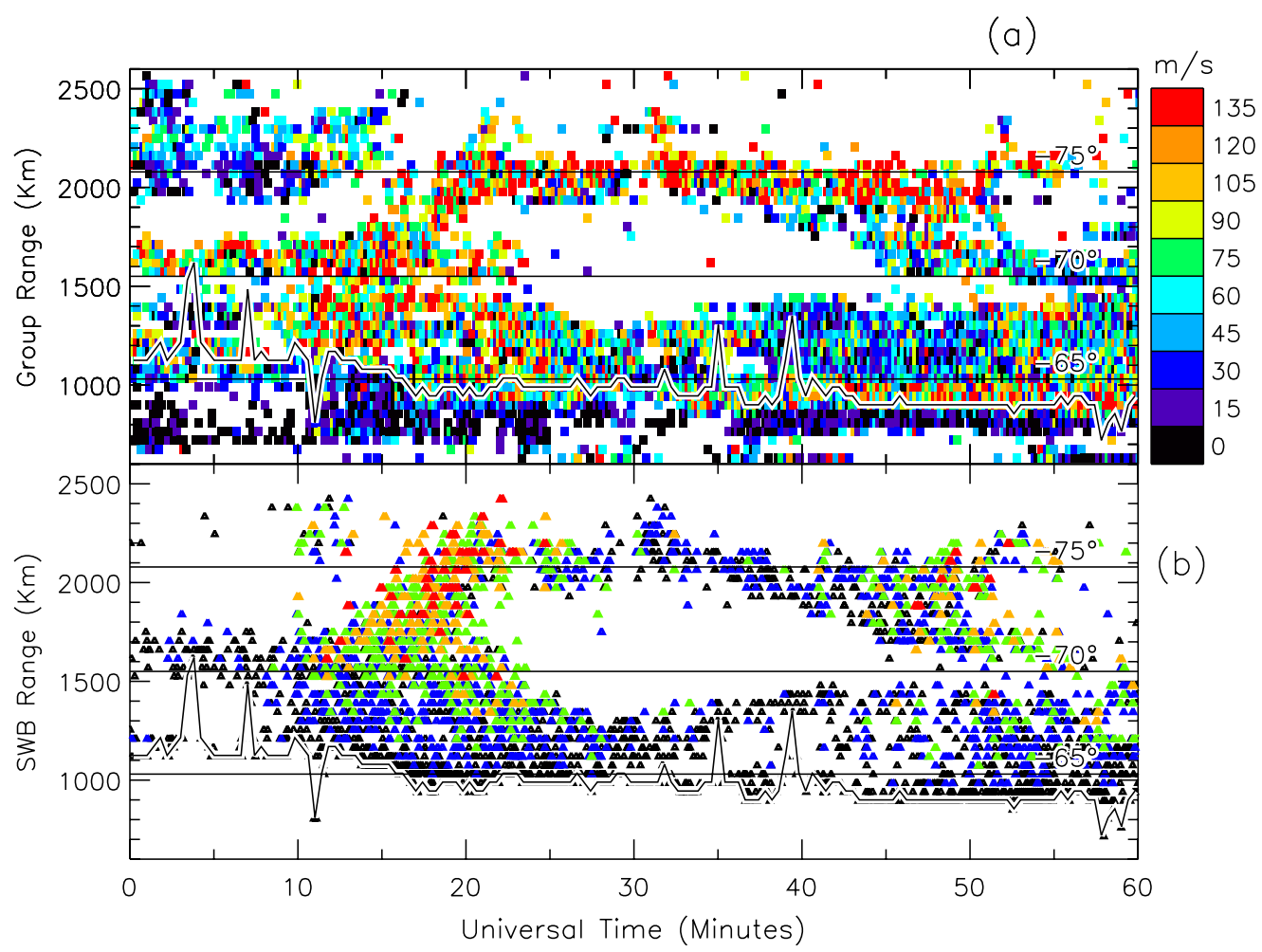

Fig. 6. (a) TIGER Tasmania observations of Doppler spectral width observed on beam 4 during 11:00 to 12:00 UT on 17 December 2005. The bold fluctuating line is the 30-s running minimum in the first SWB identified along each beam (i.e. the equatorward locus). (b) The first (black), second (blue), third (green), fourth (orange) and fifth (red) SWB determined along each beam using the algorithm described in the text. The three horizontal lines represent corrected geomagnetic latitudes of $-65^{\circ},-70^{\circ}$, and $-75^{\circ}$. Note that 3600 soundings were made per hour and the full resolution of the data cannot be reproduced at the scale of reproduction.

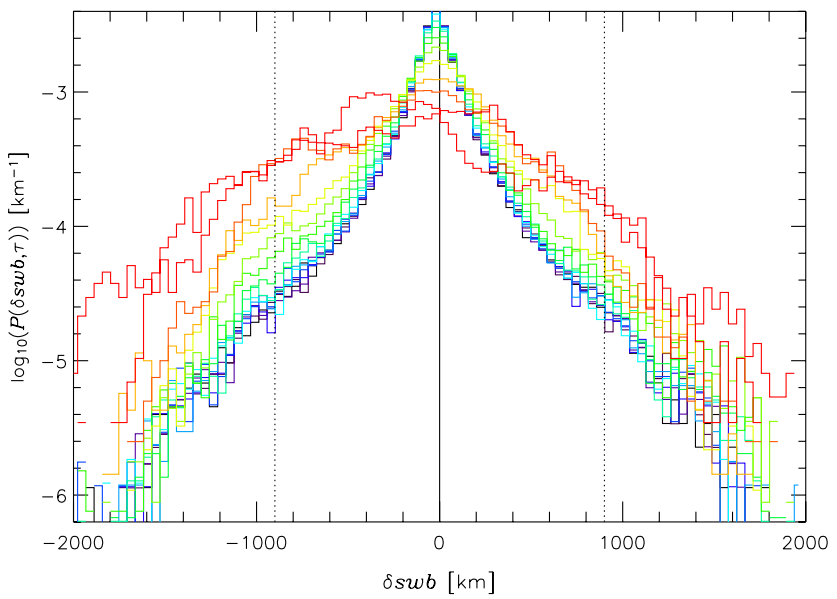

Fig. 7. Probability density functions (PDFs) of fluctuations in the SWB location $(\mathrm{km})$ identified using a threshold of $100 \mathrm{~m} \mathrm{~s}^{-1}$ throughout $\sim 32$ days of discretionary time during 4 December 2005 to 21 November 2006. The different curves correspond to temporal scales $\tau=1 \mathrm{~s}$ (black), $2 \mathrm{~s}$ (violet), .., $524288 \mathrm{~s}$ (6.1 days) (red). The PDFs were calculated using a bin size of $45 \mathrm{~km}$.
A fluctuation in the SWB location $x$ was defined as $\delta x(t, \tau)=x(t)-x(t-\tau)$ where $\tau$ is an adjustable temporal scale. It is convenient to employ octaves of temporal scale, so that $\tau=2^{i} \tau_{0}$ where $i$ is an integer and $\tau_{0}$ is the native time resolution of the data. The probability density $P(\delta x, \tau)$ of a fluctuation at scale $\tau$ is $n /(N \Delta x)$ where $N$ is the total number of $\delta x$ samples, and $\delta n$ is the number of $\delta x$ samples within bins of size $\Delta x$.

Figure 7 shows the probability density function (PDFs) of SWB fluctuations separated according to fluctuation size $\delta x$ and temporal scale $\tau$. Between $\tau \sim 1 \mathrm{~s}$ (black) and $1 \mathrm{~h}$ (green) the PDFs have a similar shape. As expected, the PDFs are sharply peaked at $\delta x=0 \mathrm{~km}$. However, they are leptokurtic out to $\sim \pm 900 \mathrm{~km}$, and then there is a Gaussian roll-off out to $\sim \pm 2000 \mathrm{~km}$. The distance $\sim \pm 900 \mathrm{~km}$ represents the maximum latitudinal extent of continuous ionospheric scatter observed using 0.5-hop propagation. The Gaussian rolloff occurs because of jumps in SWB location identified via different HF propagation modes, rather than fluctuations in the same SWB. Consistent with the central limit theorem, the PDFs converge toward a Gaussian shape across the full range of possible fluctuations as the temporal scale increases beyond $\sim 2 \mathrm{~h}$. 


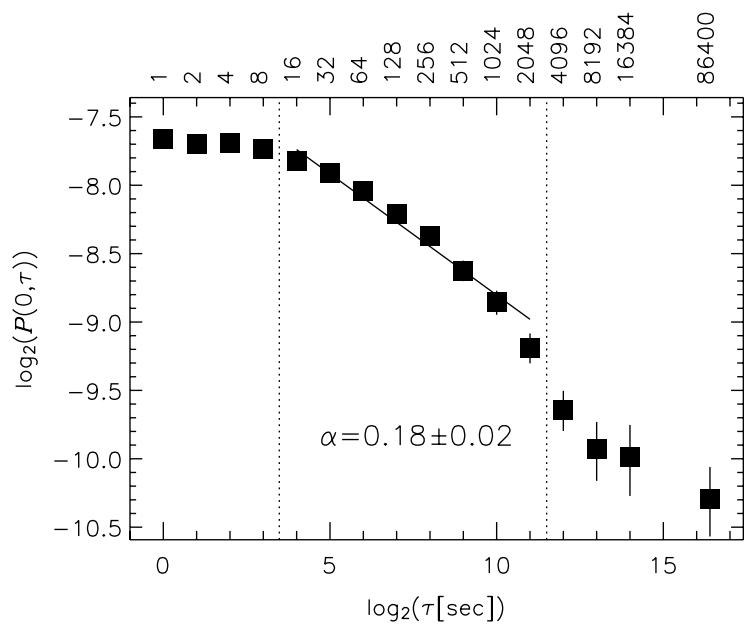

(a)

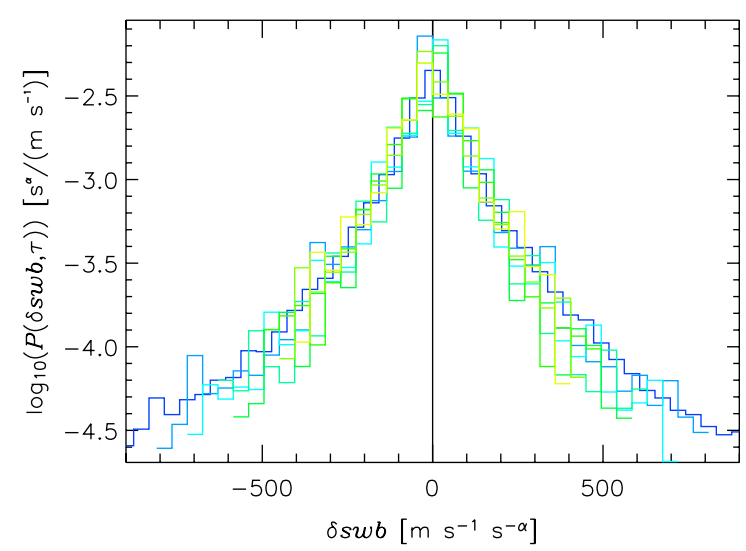

Fig. 8. (a) Scaling of the PDF peaks, $\log _{2} P(0, \tau)$ versus $\log _{2} \tau$ for the $\delta s w b$ curves shown in Fig. 7. The vertical dashed lines indicate nominal inner and outer temporal scales for the power law regime. The linear best fit to this regime yields a slope of $\alpha_{0}=0.18 \pm 0.02$ using a PDF bin size of $45 \mathrm{~km}$. The error bars assume Gaussian noise in the peaks, and are drawn at the $3 \sigma$ level. (b) Scaling collapse of the PDFs for $\tau=16 \mathrm{~s}$ to $2048 \mathrm{~s}$ and $\delta s w b<900 \mathrm{~km}$ shown in Fig. 7. The scaling exponent $\alpha_{0}=0.18$ was used, but better collapse was achieved using smaller values of $\alpha_{0}$.

Figure 7 reveals a temporal regime where the peak probability density decreases with increasing $\tau$. If the peak probability density obeys a power law then $P(0, \tau) \propto \tau^{-\alpha_{0}}$ and a plot of $\log _{2}(P(0, \tau))$ versus $\log _{2} \tau$ will be linear with the gradient giving the peak scaling exponent $\alpha_{0}$. Peak probability densities represent the probability of the time series remaining the same, or of $\delta x \rightarrow 0$. Parkinson $(2008)^{1}$ found that $\alpha_{0}$ tended to do a better job of collapsing the PDFs than $\alpha_{\mathrm{GSF}}$.

Figure 8 a shows $\log _{2}(P(0, \tau))$ versus $\log _{2} \tau$ for the PDFs of SWB fluctuations shown in Fig. 7. The quasi-linear regime between $\tau \sim 1 \mathrm{~s}$ and $8 \mathrm{~s}$ has a near zero scaling exponent and was a stronger feature prior to data conditioning. This relatively flat regime might arise because the radars do not fully resolve the fluctuations occurring at scale sizes less than the sampling volume. Another quasi-linear regime can be identi-

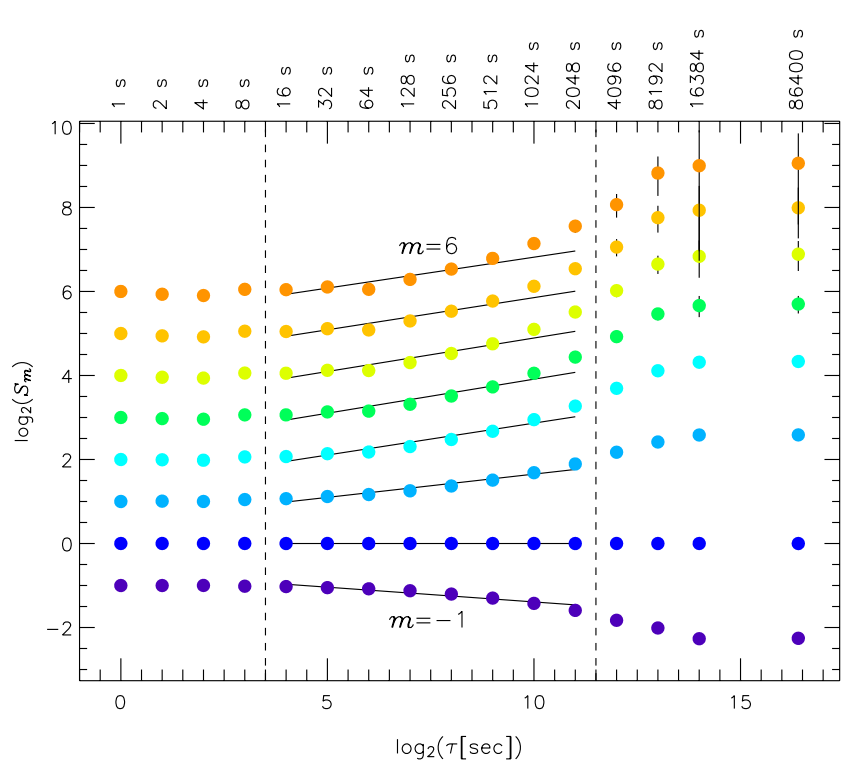

Fig. 9. A generalised structure function (GSF) analysis of the SWB fluctuations showing the variation of the moments $S_{m}(\tau)=\left\langle\left|\delta v_{s w}(t, \tau)\right|^{m}\right\rangle$ with temporal scale $\tau$ for orders $m=-1$ to 6 . Weighted least squares fits have been applied to all the moments between $\tau=16$ and $2048 \mathrm{~s}$ to estimate the individual $\zeta(m)$. Error bars are drawn at the $3 \sigma$ level but are barely visible in the plot.

fied between $\tau \sim 16 \mathrm{~s}$ and $\sim 2048 \mathrm{~s}$ (34 min). The straight line represents the results of a weighted linear regression with the error bars drawn at the $3 \sigma$ level. The estimated scaling exponent is $\alpha_{0}=0.18 \pm 0.02$ ( $1 \sigma$ error).

Note that $\log _{2}(P(0, \tau))$ is not shown for $\tau=65536 \mathrm{~s}$ because the radars rarely record scatter persisting on this dayto-night time scale. However, many samples are obtained for $\tau=1$ day because scatter tends to re-occur at the same time of day.

The self-affinity of fluctuations can be tested by attempting to re-scale and collapse the PDFs for a broad range of $\tau$ onto the same underlying curve using the transformations $P_{s}\left(\delta v_{s}, \tau\right)=\tau^{\alpha} P(\delta v, \tau)$ and $\delta v_{s}=\delta v \tau^{\alpha}$ (e.g. Hnat et al., 2002a). Figure $8 \mathrm{~b}$ shows the extent to which $\alpha_{0}=0.18$ collapses the PDFs from $\tau=16 \mathrm{~s}$ to $2048 \mathrm{~s}$ onto the same curve for SWB fluctuations out to $\pm 900 \mathrm{~km}$. There is a slight asymmetry in the curves but the smaller fluctuations agree to within statistical noise. The tails agree better for smaller values of $\alpha$.

The GSFs of the fluctuations $\delta x(t, \tau)=x(t)-x(t-\tau)$ are defined as the time average of their moments, $S_{m}(\tau)=$ $\left\langle|\delta x(t, \tau)|^{m}\right\rangle$ where $m$ is any real number, not necessarily positive. The moments are calculated out to the maximum possible order $m$ supported by the available number of samples, but the first three orders, $m=0$ (trivial), $m=1$ (averages), and $m=2$ (variances) are the most reliable (e.g. Able et al., 2006, only consider $m=1$ ). For single exponent scaling of $\delta x(t, \tau), S_{m}(\tau) \propto \tau^{\zeta(m)}$, and a log-log plot of $S_{m}$ versus $\tau$ (the "variogram") will reveal a straight line for each order $m$ 


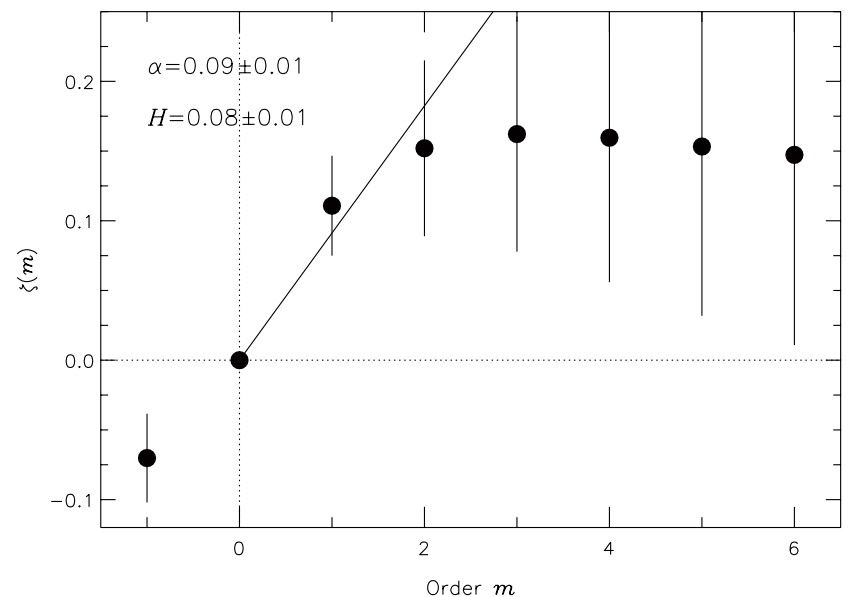

Fig. 10. The gradients of the weighted least squares curves $\zeta(m)$ estimated from Fig. 8, versus order $m$ over the range $m=-1$ to 6 . The error bars are drawn at the $3 \sigma$ level. The gradient of the weighted least squares curve to the $\zeta(m)$ points between $m=0$ and $m=2$ gives $\alpha_{\mathrm{GSF}}=0.09 \pm 0.01$ ( $1 \sigma$ error).

with gradients $\zeta(m)$. If the time series of $x$ is mono-fractal, then $\zeta(m)=\alpha_{\mathrm{GSF}} m$ with a single scaling exponent $\alpha_{\mathrm{GSF}}$. The function $\zeta(m)$ may be nonlinear because large, rare fluctuations were under-sampled or because the data is multi-fractal.

Ideally, GSF analysis requires very large sample sizes (i.e. millions) to reduce statistical errors in the higher order moments. Splitting our results into small sub-intervals of magnetic local time or interplanetary magnetic field, for example, would be unreliable using only 113538 samples.

Figure 9 shows the variogram of SWB fluctuations with the moments $S_{m}(\tau)$ calculated for $m=-1$ to 6 and for $\tau$ ranging from $1 \mathrm{~s}$ to 1 day. All the SWB fluctuations $>900 \mathrm{~m} \mathrm{~s}^{-1}$ have been rejected because they represent fluctuations in the HF propagation conditions and they clearly belong to a different physical regime. The estimation of the higher order statistical moments will be unreliable for this highly conditioned SuperDARN data which cannot measure SWB fluctuations beyond the practical limit of $\sim 900 \mathrm{~km}$ due to limits imposed by ionospheric refraction. Although some fluctuations $>900 \mathrm{~km}$ are probably genuine, these have been rejected in the interests of rigour.

Figure 9 shows that even the low order structure functions are curves: strictly the gradients $\zeta(m)$ evolve continuously across the full range of $\tau$. However, three separate quasilinear regimes can be identified. Between $1 \mathrm{~s}$ and $\sim 10 \mathrm{~s}$ the curves are nearly flat, and the corresponding gradients nearly zero. This is taken to indicate the spatial and temporal averaging intrinsic to the SuperDARN design does not permit accurate estimation of fluctuations beneath $\tau \sim 10$ s (Parkinson, $2008^{1}$ ). The gradients of the individual $S_{m}(\tau)$ are related between $\tau \sim 10 \mathrm{~s}$ and $2048 \mathrm{~s}$ (34 min), but thereafter diverge due to deteriorating statistics combined with the transition to a larger scale regime.
Figure 10 shows $\zeta(m)$ versus order $m$ (the " $\zeta$ plot") with the gradients $\zeta$ estimated between $\tau \sim 16 \mathrm{~s}$ and $2048 \mathrm{~s}$ (34 min) in Fig. 8. Changing the scaling limits by one octave does not change the main results of this study. The linearity of the points breaks down for $m=2$ and this arises from the finite sample sizes and possible multi-fractal behaviour. The scaling exponent estimated by fitting a weighted linear regression to orders $m=0$ to 2 gives $\alpha_{\mathrm{GSF}}=0.09 \pm 0.01$ ( $1 \sigma$ statistical error). This result was obtained by constraining the fit to pass through the origin because $\zeta(m)=0$ by definition.

The large volume sampling used by SuperDARN radars may also affect the present results for $\tau>10 \mathrm{~s}$ and improved radar measurements and analysis techniques may result in a different value for $\alpha$.

\section{Summary and discussion}

The physical explanation of SuperDARN spectral widths and the SWB is controversial and no study has proven the overriding importance of any of the mechanisms given in the introduction. Any comprehensive theory of the spectral widths must account for the complicated behaviour of the F-region plasma drifting across the nightside SWB. The main results of this paper are summarised as follows:

1. As of yet there is no evidence for a distinct transition in the intensity of decametre-scale irregularities drifting across the HF radar SWB (Fig. 1a).

2. There is a relatively rapid decrease in bursty LOS Doppler velocity, $v_{\text {LOS }}$, across the SWB (Fig. 1b). This is consistent with a decrease in the average meso-scale flow speed across the SWB.

3. The average 2-D beam swinging vectors also decrease across the SWB (Fig. 1c). However, the intermittency of the 2-D flow increases at the SWB, and the flows become more homogeneous when crossing the SWB (Fig. 2).

4. The existence of large (small) spectral widths poleward (equatorward) of the SWB (Fig. 1d) are consistent with an increase in the homogeneity of the small-scale flows crossing the SWB.

5. The transition across the SWB is more distinct in the spectral widths than the meso-scale flows; hence the process controlling formation of the SWB is stronger at smaller scales.

6. The Doppler spectral shapes change from predominantly Lorentzian above the SWB to predominantly Gaussian below the SWB (Fig. 1e). However, the largest spectral widths are associated with Gaussian spectral shapes both above and below the SWB (Fig. 3). The majority of indeterminate spectral shapes were observed below the SWB. 
7. There were complicated patterns in the distribution of spectral width and spectral shape in the region of the SWB (Fig. 1e). Above the SWB, there were small isolated patches of Gaussian spectral shape scattered amongst the predominantly Lorentzian shapes. Below the SWB, patches of Gaussian shape expanded equatorward through a general background of indeterminate shape.

8. Although there was a tendency for patches of higher $v_{\text {LOS }}$, spectral width, and spectral shape (Fig. 1b, d, e) to coincide, the relationship was not clear, as might be the case if there were only a simple linear relationship between the different parameters.

9. Double-peaked Doppler spectra were concentrated in the region above the SWB, but not beneath it (Fig. 1f), suggesting the small-scale turbulence was more intense poleward of the SWB.

10. Fluctuations in the SWB exhibited an approximately scale-free regime between $\tau \sim 16 \mathrm{~s}$ and $\sim 2048 \mathrm{~s}$ (34 min) (Figs. 8 and 9). The power law scaling exponents were $\alpha_{0}=0.18 \pm 0.02$ and $\alpha_{\mathrm{GSF}}=0.09 \pm 0.01$ ( $1 \sigma$ statistical errors). These preliminary values are much smaller than the value expected for MHD turbulence (Irosnikov, 1964; Kraichnan, 1965).

Although these results do not prove any of the mechanisms proposed to explain the large spectral widths, they do provide clues. There was a transition from predominantly Lorentzian spectral shape above the SWB to predominantly Gaussian shape below the SWB. Combined with collective scattering wave theory (Hanuise et al., 1993), this implies there was a transition from a fast flowing, turbulent plasma with a correlation length of velocity fluctuations less than the scattering wavelength $(\sim 25 \mathrm{~m})$, to a slower moving plasma with a correlation length greater than the scattering wavelength. Perhaps an advanced non-linear turbulence theory combined with collective scattering wave theory can explain the observations.

The association between large spectral width and Gaussian spectral shape (Figs. 3, 4) suggests that many of the large spectral widths actually indicate the spread of $v_{\text {LOS }}$ throughout the integration time and sampling volume. The large spectral widths may be caused by a spectrum of smallscale vortices of various scale sizes overlapping the radar observation cells in various ways. The results of Huber and Sofko (2000) imply the number of convection vortices increases with decreasing scale size $(<26 \mathrm{~km})$ and decreasing lifetime ( $<4 \mathrm{~s})$, perhaps forming a scale-free distribution.

Parkinson (2006a) used GSF analysis to show that SuperDARN velocity fluctuations are a dynamic fractal process with associated intense flow burst activity extending down to very small temporal scales. The results suggest the velocity fluctuations above (below) the SWB were mono-fractal (multi-fractal) on time scales from $\sim 2 \mathrm{~h}$ down to $1 \mathrm{~min}$, and possibly much less. The scaling exponents were smaller for echoes with large spectral width $>100 \mathrm{~m} \mathrm{~s}^{-1}$, mostly found above the SWB. For example, the scaling exponent $\alpha_{\mathrm{GSF}}$ was only $0.12 \pm 0.06$ poleward of the nightside SWB, yet $0.21 \pm 0.06$ equatorward of it. This suggests a fundamental transition in the dynamics of electric field turbulence traversing the SWB.

The analysis of fluctuations in the location of the SWB location itself reported here yielded scaling exponents of $\alpha_{0}=0.18 \pm 0.02$ and $\alpha_{\mathrm{GSF}}=0.09 \pm 0.01$ ( $1 \sigma$ statistical errors), closer to the scaling exponent of the velocity fluctuations found above the SWB $(0.12 \pm 0.06)$. These scaling exponents are unusually small, indicating complexity greater than that expected for MHD turbulence (Irosnikov, 1964; Kraichnan, 1965). Any theory of the formation of the SWB must account for this complexity.

Parkinson $(2008)^{1}$ found that peak scaling exponents were generally larger than GSF scaling exponents, and they were also closer to the value required to optimise scaling collapse of the PDFs. Note also that estimates of the scaling exponents are probably affected by the design and operation of SuperDARN radars, the FITACF algorithm, and the technique used to identify the SWB.

It is tempting to identify a characteristic time scale for the equatorward expanding patches of flow velocity (Fig. 1b, c), spectral width (Fig. 1d), and spectral shape (Fig. 1e), but unrepresentative scales can manifest in short segments of fractal data. Scatter plots showed no strong correlations between the radar parameters, as might be expected for a linear system. The non-linear interactions causing the fractal behaviour of the plasma motion might help to explain why the patches of enhanced $v_{\text {LOS }}$, spectral width, and spectral shape were only weakly correlated.

Spatial and temporal variations in the magnetospheric driver causing the large SuperDARN spectral widths will play an important role in forming the SWB. For the event analysed here, the SWB formed at the poleward edge of energetic electron precipitation, and thus a step-like increase in the ionospheric Pedersen conductance, $\Sigma_{p}$ (see Parkinson et al., 2002, 2004, 2005a; Chisham et al., 2005). Figure 6 of Parkinson et al. (2002) showed a DMSP F14 SS J/4 spectrogram of precipitating particles coincident with our Fig. 1 radar observations. Hardy et al. (1987) gave formulae for estimating $\Sigma_{p}$ using the electron energy flux and mean electron energy, as measured using the SS J/4 detectors. Figure 6 of Parkinson et al. (2002) combined with Hardy et al. (1987) suggest the SWB was aligned with a step-like increase in Pedersen conductance on 10 December 1999.

Borovosky and Bonnel (2001) modeled the mapping of vortices from the magnetosphere to the ionosphere and showed the suppression of negative centred vortices of characteristic scale length less than $l_{\perp}=\left(\Sigma_{p} / \mathrm{Q}_{u p}\right)^{1 / 2}$ where $\mathrm{Q}_{u p}$ is the upward field line conductance. Taking $\Sigma_{p} \sim 10 \mathrm{mho}$ for the auroral oval gives $l_{\perp}=112 \mathrm{~km}$ compared with the 
$\sim 45 \times 100 \mathrm{~km}$ scale size of SuperDARN observation cells. Positive centred vortices map to the ionosphere at scales $<112 \mathrm{~km}$ but probably decay quickly through Joule heating. Weimer et al. (1985) had previously used Dynamics Explorer I and II measurements to show the role of enhanced Pedersen conductance in suppressing short-scale electric field fluctuations and forming field-parallel potential drops and currents above auroral arcs.

The 2-D meso-scale velocities decay across the SWB (Fig. 1b, c). This may be partly due to plasma pressure breaking the motion of flux tubes across the open-closed magnetic field line boundary in the magnetotail. However, the well known tendency for ionospheric electric fields to be expelled from regions of enhanced $\Sigma_{p}$ may also partly account for the decay. As explained above, the short-scale electric field fluctuations causing the large spectral widths observed in the polar cap (Fig. 1) are probably suppressed in the nightside auroral oval by particle-precipitation enhanced Pedersen conductance. The effect is analogous to the suppression of electric fields parallel to the surface of a conductor, yet not perpendicular to it.

Statistical studies of spectral width (Woodfield et al., 2002; Parkinson et al., 2003b) show that the spectral widths tend to be lower in the sunlit summer hemisphere than in the dark winter hemisphere. Likewise, Golovchanskaya (2007) showed that electric field turbulence was suppressed in the sunlit summer ionosphere. It is well known the E-region conductance decreases with solar-zenith angle. This may be further experimental evidence supporting the notion that enhanced Pedersen conductance suppresses small-scale electric field fluctuations.

The magnetospheric substorm is thought to exhibit nonlinear dynamics akin to second-order phase transition theory (e.g. Chang, 1992; Ukhorskiy et al., 2003). In the current disruption paradigm for substorm onset, the cross tail current may undergo a transition to multi-fractal plasma turbulence in which current and magnetic fluctuations interact (Lui, 2001; Vörös et al., 2003). A future study applying complexity science techniques to the behaviour of the HF radar velocities, spectral widths and SWB may reveal ionospheric signatures of these magnetospheric processes.

Ultimately, new radar observations with better angular and temporal resolution may be required to directly observe the underlying structure of irregularities and flows causing the complicated spectral width behaviour reported in this paper.

Acknowledgements. This work was supported by the Australian Research Council, the Australian Antarctic Science Advisory Council, the Australian Academy of Sciences, and the TIGER Consortium Partners (La Trobe University, Australian Antarctic Division, DSTO Intelligence Surveillance and Reconnaissance Division, IPS Radio and Space Services, Monash University, University of Newcastle). The authors thank A. Koustov and D. Danskin for analysing the TIGER Tasmania data with their Burg spectral technique, and for their insightful discussions. H. Ye and the numerous people who contributed to the operation of the TIGER radars are thanked.
Topical Editor M. Pinnock thanks E. A. Woodfield and another anonymous referee for their help in evaluating this paper.

\section{References}

Able, G. A., Freeman, M. P., and Chisham, G.: Spatial structure of ionospheric convection velocities in regions of open and closed magnetic field topology, Geophys. Res. Lett., 33, L24103, doi:10.1029/2006GL027919, 2006.

Anderson, P. C., Hanson, W. B., Heelis, R. A., Craven, J. D., Baker, D. N., and Frank, L. A.: A proposed production model of rapid subauroral ion drifts and their relationship to substorm evolution, J. Geophys. Res., 98, 6069-6078, 1993.

André, R., Pinnock, M., and Rodger, A. S.: On the SuperDARN autocorrelation function observed in the ionospheric cusp, Geophys. Res. Lett., 26, 3353-3356, 1999.

André, R., Pinnock, M. Villain, J.-P., and Hanuise, C.: On the factors conditioning the Doppler spectral width determined from SuperDARN HF radars, Int. J. Geomag. Aeronomy, 2, 77-86, 2000.

André, R., Villain, J.-P., Krasnoselskikh, V., and Hanuise, C.: Turbulence characteristics inside ionospheric small-scale expanding structures observed with SuperDARN HF radars, J. Geophys. Res., 105, 20 869-20 884, 2000.

André, R., Hanuise, C., Villain, J.-P., and Krasnoselskikh, V.: Turbulence characteristics inside ionospheric small-scale expanding structures observed with SuperDARN HF radars, Ann. Geophys., 21, 1839-1845, 2003, http://www.ann-geophys.net/21/1839/2003/.

Bak, P., Tang, C., and Wiesenfeld, K.: Self-organized criticality: An explanation of 1/f noise, Phys. Rev. Lett., 59(4), 381-384, 1987.

Baker, K. B., Dudeney, J. R., Greenwald, R. A., Pinnock, M., Newell, P. T., Rodger, A. S., Mattin, N., and Meng, C.-I.: HF radar signatures of the cusp and low-latitude boundary layer, J. Geophys. Res., 100, 7671-7695, 1995.

Bilitza, D.: International Reference Ionosphere 2000, Radio Sci., 36, 261-275, 2001.

Chang, T. S.: Low-dimensional behaviour and symmetry breaking of stochastic systems near criticality - can these effects be observed in space and in the laboratory?, IEEE Trans. Plasma Sci., 20, 691, 1992.

Borovsky, J. E. and Bonnell, J.: The DC electrical coupling of flow vortices and flow channels in the magnetosphere to the resistive ionosphere, J. Geophys. Res., 106, 28 967-28 994, 2001.

Chapman, S. C., Hnat, B., Rowlands, G., and Watkins, N. W.: Scaling collapse and structure functions: identifying self-affinity in finite length time series, Nonlin. Processes Geophys., 12, 767774,2005 , http://www.nonlin-processes-geophys.net/12/767/2005/.

Chisham, G. and Freeman, M. P.: A technique for accurately determining the cusp-region polar cap boundary using SuperDARN HF radar measurements, Ann. Geophys., 21, 983-996, 2003, http://www.ann-geophys.net/21/983/2003/.

Chisham, G. and Freeman, M. P.: An investigation of latitudinal transitions in the SuperDARN Doppler spectral width parameter at different magnetic local times, Ann. Geophys., 22, 1187-1202, 2004a, http://www.ann-geophys.net/22/1187/2004/. 
Chisham, G., Freeman, M. P., and Sotirelis, T.: A statistical comparison of SuperDARN spectral width boundaries and DMSP particle precipitation boundaries in the nightside ionosphere, Geophys. Res. Lett., 31, L02804, doi:10.1029/2003GL019074, 2004b.

Chisham, G., Freeman, M. P., Sotirelis, T., Greenwald, R. A., Lester, M., and Villain, J.-P.: A statistical comparison of SuperDARN spectral width boundaries and DMSP particle precipitation boundaries in the morning sector ionosphere, Ann. Geophys., 23, 733-743, 2005, http://www.ann-geophys.net/23/733/2005/.

Chisham, G., Lester, M., Milan, S. E., Freeman, M. P., Bristow, W. A., et al.: A decade of the Super Dual Auroral Radar Network (SuperDARN): scientific achievements, new techniques and future directions, Surv. Geophys., 28, 33-109, 2007.

Cowley, S. W. H. and Lockwood, M.: Excitation and decay of solar wind-driven flows in the magnetosphere-ionosphere system, Ann. Geophys., 10, 103-115, 1992,

http://www.ann-geophys.net/10/103/1992/.

Danskin, D. W., Koustov, A. V., Makarevitch, R. A., and Lester, M.: Observations of double-peaked E region coherent spectra with the CUTLASS Finland HF radar, Radio Sci., 39, RS2006, doi:10.1029/2003RS002932, 2004.

de la Beaujardière, O., Lyons, L. R., Ruohoniemi, J. M., FriisChristensen, E., Danielsen, C., Rich, F. J., and Newell, P. T.: Quiet-time intensifications along the poleward boundary near midnight, J. Geophys. Res., 99, 287-298, 1994.

Dyson, P. L. and Devlin, J. C.: The Tasman International Geospace Environment Radar, The Physicist (The Australian Institute of Physics), 37, 48-53, March/April 2000.

Dyson, P. L., Devlin, J. C., Parkinson, M. L., and Whittington, J. S.: The Tasman International Geospace Environment Radar (TIGER) - Current Development and Future Plans, IEEE Proc. Int. Conference on Radar, IEEE Catalogue No. 03EX695C, 282287, 2003.

Dyson, P. L., Parkinson, M. L., Conde, M., and Devlin, J. C.: New investigations in magnetosphere-ionosphere-thermosphere processes and their impact on space weather, Proceedings, NSSA Space Science Conference, Melbourne, 13-15 September 2005.

Farley, D. T.: A plasma instability resulting in field-aligned irregularities in the ionosphere, J. Geophys. Res., 68, 6083-6093, 1963.

Freeman, M. P., Ruohoniemi, J. M., and Greenwald, R. A.: The determination of time-stationary 2-D convection patterns with single station radars, J. Geophys. Res., 96, 15 735-15 749, 1991.

Freeman, M. P. and Chisham, G.: On the probability distributions of SuperDARN radar spectral width in the cusp and non-cusp regions, SuperDARN Workshop, Kiljava, Finland, 19-23 May 2003.

Golovchanskaya I. V., Ostapenko, A. A., and Kozelov, B. V.: Relationship between the high-latitude electric and magnetic turbulence and the Birkeland field-aligned currents, J. Geophys. Res., 111, A12301, doi:10.1029/2006JA011835, 2006.

Golovchanskaya, I. V.: On the seasonal variation of electric and magnetic turbulence at high latitudes, Geophys. Res. Lett., 34, L13103, doi:10.1029/2007GL030125, 2007.

Greenwald, R. A., Baker, K. B., Hutchins, R. A., and Hanuise, C.: An HF phased-array radar for studying small-scale structure in the high-latitude ionosphere, Radio Sci., 20, 63-79, 1985.
Greenwald, R. A., Baker, K. B., Dudeney, J. R., et al.: DARN/SuperDARN: A global view of the dynamics of highlatitude convection, Space Sci. Rev., 71, 761-796, 1995.

Hnat, B., Chapman, S. C., Rowlands, G., Watkins, N. W., and Farrell, W. M.: Finite size scaling in the solar wind magnetic field energy density as seen by WIND, Geophys. Res. Lett., 29(10), 1446, doi:10.1029/2001GL014587, 2002a.

Hnat, B., Chapman, S. C., Rowlands, G., Watkins, N. W., and Freeman, M. P.: Scaling of the solar wind $\varepsilon$ and the $\mathrm{AU}, \mathrm{AL}$ and $\mathrm{AE}$ indices as seen by WIND, Geophys. Res. Lett., 29(22), 2078, doi:10.1029/2002GL016054, 2002 b.

Hnat, B., Chapman, S. C., Rowlands, G., Watkins, N. W., and Freeman, M. P.: Scaling in long term data sets of geomagnetic indices and solar wind $\varepsilon$ as seen by WIND spacecraft, Geophys. Res. Lett., 30(22), 2174, doi:10.1029/2003GL018209, 2003.

Hnat, B., Chapman, S. C., and Rowlands, G.: Scaling and a FokkerPlank model for fluctuations in geomagnetic indices and comparison with solar wind $\varepsilon$ as seen by WIND and ACE, J. Geophys. Res., 110, A08206, doi:10.1029/2004JA010824, 2005.

Hardy, D. A., Gussenhoven, M. S., and Raistrick, R.: Statistical and functional representations of the pattern of auroral energy flux, number flux, and conductivity, J. Geophys. Res., 92, 12275 12 294, 1987.

Hanuise, C., Villain, J. P., Gresillon, D., Cabrit, B., Greenwald, R. A., and Baker, K. B.: Interpretation of HF radar ionospheric Doppler spectra by collective wave scattering theory, Ann. Geophys., 11, 29-39, 1993, http://www.ann-geophys.net/11/29/1993/.

Huber M. and Sofko G. J.: Small-scale vortices in the high-latitude F region, J. Geophys. Res., 105(A9), 20 885-20 897, 2000.

Iroshnikov, P. S.: Soviet Astronomy, 7, 742-750, 1964.

Kraichnan, R. H.: Inertial range spectrum of hydromagnetic turbulence, Phys. Fluids, 8, 1385-1387, 1965.

Lester, M., Milan, S. E., Besser, V., and Smith, R.: A case study of HF radar spectra and $630.0 \mathrm{~nm}$ auroral emission in the premidnight sector, Ann. Geophys., 19, 327-339, 2001, http://www.ann-geophys.net/19/327/2001/.

Lui, A. T. Y.: Multifractal and intermittent nature of substormassociated magnetic turbulence in the magnetotail, J. Atmos. Sol.-Terr. Phy., 63, 1379-1385, 2001.

Moen, J., Carlson, H. C., Milan, S. E., Shumilov, N., Lybekk, B., Sandholt, P. E., and Lester, M.: On the collocation between dayside auroral activity and coherent HF radar backscatter, Ann. Geophys., 18, 1531-1549, 2001,

http://www.ann-geophys.net/18/1531/2001/.

Parkinson, M. L., Monselesan, D. P., Smith, P. R., Dyson, P. L., and Morris, R. J.: Digital ionosonde measurements of the height variation of drift velocity in the southern polar cap ionosphere: initial results, J. Geophys. Res., 102, 24 075-24 090, 1997.

Parkinson, M. L., Breed, A. M., Dyson, P. L., and Morris, R. J.: Application of the Dopplionogram to Doppler-sorted interferometry measurements of ionospheric drift velocity, Radio Sci., 34, 899912, 1999a.

Parkinson, M. L., Breed, A. M., Dyson, P. L., and Morris, R. J.: Signatures of the ionospheric cusp in digital ionosonde measurements of plasma drift above Casey, Antarctica, J. Geophys. Res., 104(A10), 22 487-22 498, 1999 b.

Parkinson, M. L., Dyson, P. L., Pinnock, M., Devlin, J. C., Hairston, M. R., Yizengaw, E., and Wilkinson, P. J.: Signatures of the mid- 
night open-closed magnetic field-line boundary during balanced dayside and nightside reconnection, Ann. Geophys., 20, 16171630, 2002, http://www.ann-geophys.net/20/1617/2002/.

Parkinson, M. L., Pinnock, M., Ye, H., Hairston, M. R., Devlin, J. C., Dyson, P. L., Morris, R. J., and Ponomarenko, P.: On the lifetime and extent of an auroral westward flow channel (AWFC) observed during a magnetospheric substorm, Ann. Geophys., 21, 893-913, 2003a,

http://www.ann-geophys.net/21/893/2003/.

Parkinson, M. L., Devlin, J. C., Ye, H., Waters, C. L., Dyson, P. L., Breed, A. M., and Morris, R. J.: On the occurrence and motion of decametre-scale irregularities in the sub-auroral, auroral, and polar cap ionosphere, Ann. Geophys., 21, 1847-1868, 2003b, http://www.ann-geophys.net/21/1847/2003/.

Parkinson, M. L., Chisham, G., Pinnock, M., Dyson, P. L., and Devlin, J. C.: Magnetic local time, substorm, and particle precipitation-related variations in the behaviour of SuperDARN Doppler spectral widths, Ann. Geophys., 22, 4103-4122, 2004, http://www.ann-geophys.net/22/4103/2004/.

Parkinson, M. L., Pinnock, M., Dyson, P. L., and Devlin, J. C.: Signatures of the nightside open-closed magnetic fieldline boundary during moderately disturbed conditions and ionospheric substorms, Adv. Space Res., 36(10), 1791-1796, doi:10.1016/j.asr.2005.06.082, 2005a.

Parkinson, M. L.: Dynamical critical scaling of electric field fluctuations in the greater cusp and magnetotail implied by HF radar observations of F-region Doppler velocity, Ann. Geophys., 24, 689-705, 2006a,

http://www.ann-geophys.net/24/689/2006/.

Parkinson, M. L., Dyson, P. L., and Pinnock, M.: On the occurrence of auroral westward flow channels and substorm phase, Adv. Space Res., 38, 1755-1762, 2006b.

Parkinson, M. L., Healey, R. C., and Dyson, P. L.: Solar cycle changes in the geo-effectiveness of small-scale solar wind turbulence measured by Wind and ACE at $1 \mathrm{AU}$, Ann. Geophys., 25, 1183-1197, 2007, http://www.ann-geophys.net/25/1183/2007/.

Ponomarenko, P. V. and Waters, C. L.: The role of Pc 1-2 waves in spectral broadening of SuperDARN echoes from high latitudes, Geophys. Res. Lett., 30(3), 1122, doi:10.1029/2002GL016333, 2003.

Ponomarenko, P. V. and Waters, C. L.: Spectral width of SuperDARN echoes: Measurement, use, and physical interpretation, Ann. Geophys., 24, 115-128, 2006,

http://www.ann-geophys.net/24/115/2006/.

Ponomarenko, P. V., Waters, C. L., and Menk, F. W.: Factors determining spectral width of HF echoes from high latitude, Ann. Geophys., 25, 675-687, 2007,

http://www.ann-geophys.net/25/675/2007/.

Rodger, A. S., Moffett, R. J., and Quegan, S.: The role of ion drift in the formation of ionisation troughs in the mid- and high-latitude ionosphere - a review, J. Atmos. Terr. Phys., 54, 1-30, 1992.

Ruohoniemi, J. M. and Baker, K. B.: Large-scale imaging of highlatitude convection with Super Dual Auroral Radar Network HF radar observations, J. Geophys. Res., 103, 20 797-20 811, 1998.

Rowlands, G.: Non-linear phenomena in science and engineering, Ellis Horwood Limited, Chichester, England, 1990.

Schiffler, A., Sofko, G., Newell, P. T., and Greenwald, R.: Mapping the outer LLBL with SuperDARN double-peaked spectra,
Geophys. Res. Lett., 24, 3149-3152, 1997.

Sellek, R., Bailey, G. J., Moffett, R. J., Heelis, R. A., and Anderson, P. C.: Effects of large zonal plasma drifts on the subauroral ionosphere, J. Atmos. Terr. Phys., 53, 557-565, 1991.

Sundkvist, D., Krasnoselskikh, V., Shukla, P. K., Vaivads, A., André, M., Buchert, S., and Rème, H.: In situ multi-satellite detection of coherent vortices as manifestation of Alfvénic turbulence, Nature, 436, 825-828, doi:10.1038/nature03931, 2005.

Ukhorskiy, A. Y., Sitnov, M. I., Sharma, A. S., and Papadopoulos, K.: Combining global and multi-scale features in a description of the solar wind-magnetosphere coupling, Ann. Geophys., 21, 1913-1929, 2003, http://www.ann-geophys.net/21/1913/2003/.

Villain, J. P., Caudal, G., and Hanuise, C.: A SAFARI-EISCAT comparison between the velocity of $F$ region small-scale irregularities and ion drift, J. Geophys. Res., 90, 8433-8444, 1985.

Villain, J. P., Greenwald, R. A., Baker, K. B., and Ruohoniemi, J. M.: HF radar observations of $\mathrm{E}$ region plasma irregularities produced by oblique electron streaming, J. Geophys. Res., 92, 12 327-12 342, 1987.

Villain, J. P., André, R., Hanuise, C., and Grésillon, D.: Observation of the high latitude ionosphere by HF radars: interpretation in terms of collective wave scattering and characterization of turbulence, J. Atmos. Terr. Phys., 58, 943-958, 1996.

Villain, J. P., André, R., Pinnock, M., Greenwald, R. A., and Hanuise, C.: A statistical study of the Doppler spectral width of high latitude ionospheric F region recorded with SuperDARN coherent HF radars, Ann. Geophys., 20, 1769-1781, 2002, http://www.ann-geophys.net/20/1769/2002/.

Vörös, Z., Baumjohann, W., Nakamura, R., et al.: Multi-scale magnetic field intermittence in the plasma sheet, Ann. Geophys., 21, 1955-1964, 2003, http://www.ann-geophys.net/21/1955/2003/.

Walker, A. D. M., Greenwald, R. A., and Baker, K. B.: Determination of the fluctuation level of ionospheric irregularities from radar backscatter measurements, Radio Sci., 22, 689-705, 1987.

Weimer, D. R., Goertz, C. K., Gurnett, D. A., Maynard, N. C., and Burch, J. L.: Auroral zone electric fields from DE 1 and 2 at magnetic conjunctions, J. Geophys. Res., 90, 7479-7494, 1985.

Woodfield, E. E., Davies, J. A., Lester, M., Yeoman, T. K., Eglitis, P., and Lockwood, M.: Nightside studies of coherent HF radar spectral width behaviour, Ann. Geophys., 20, 1399-1413, 2002, http://www.ann-geophys.net/20/1399/2002/.

Woodfield, E. E., Hosokawa, K., Milan, S. E., Sato, N., and Lester, M.: An inter-hemispheric, statistical study of nightside spectral width distributions from coherent HF scatter radars, Ann. Geophys., 20, 1921-1934, 2002,

http://www.ann-geophys.net/20/1921/2002/.

Wright, D. M., Davies, J. A., Robinson, T. R., Chapman, P. J., Yeoman, T. K., Thomas, E. C., Lester, M., Cowley, S. W. H., Stocker, A. J., Horne, R. B., and Honary, F.: Space Plasma Exploration by Active Radar (SPEAR): an overview of a future radar facility, Ann. Geophys., 18, 1248-1255, 2000, http://www.ann-geophys.net/18/1248/2000/.

Wright, D. M., Yeoman, T. K., Baddeley, L. J., et al.: High resolution observations of spectral width features associated with ULF wave signatures in artificial HF radar backscatter, Ann. Geophys., 22, 169-182, 2004, http://www.ann-geophys.net/22/169/2004/. 